\title{
Anatomical Variants in Frontal Recess Region and their Impact on Frontal Sinus Surgery in Chronic Sinusitis
}

\author{
Omer Abd El-Moneim El-Banhawy ${ }^{1}$, Adel Tharwat Atalla ${ }^{1}$, Mohamed Ramadan El-Kholy ${ }^{2}$, \\ Ahmed Abd El-Halim Mohammed ${ }^{1}$, Ahmed El-Mohamedy El-Neily ${ }^{3}$ \\ ${ }^{1}$ E.N.T. Department, Faculty of Medicine, Menoufia University, Egypt \\ ${ }^{2}$ Radiology Department, Faculty of Medicine, Menoufia University, Egypt \\ ${ }^{3}$ E. N.T. Department, Elminshawy General Hospital, Tanta, Egypt \\ Email address: \\ Elneily2003@hotmail.com (A. El-Mohamedy El-Neily)

\section{To cite this article:} \\ Omer Abd El-Moneim El-Banhawy, Adel Tharwat Atalla, Mohamed Ramadan El-Kholy, Ahmed Abd El-Halim Mohammed, Ahmed \\ El-Mohamedy El-Neily. Anatomical Variants in Frontal Recess Region and their Impact on Frontal Sinus Surgery in Chronic Sinusitis. \\ American Journal of Health Research. Vol. 3, No. 3, 2015, pp. 140-145. doi: 10.11648/j.ajhr.20150303.15
}

\begin{abstract}
Objective: To study the prevalence of anatomical variants in frontal recess region and their impact on frontal sinus surgery. Setting: University referral center. Patients and Methods: This was a clinical trial prospective study approved by Menoufia University research ethics board (REB) and included 50 Egyptian patients selected from the ENT department of Menoufia University between June 2011 to November 2014, who were suffering from chronic frontal sinusitis. Preoperative CT with coronal, axial and sagittal cuts were examined to show anatomical variants. Frontalsinusotomy was doneendoscopically and surgicall easiness was evaluated. Results: Increased aggernasi cell size was associated with increased operative easiness. Increase danteroposteri or diameter of frontal sinus ostium was associated with increased operative easiness. Type 3 frontoethmoidal air cell and interfrontal sinusseptal cells were more difficult in surgery than other frontoethmoidal air cells. Operativeeasiness correlated with different types of uncinate process superior attachment. Conclusions: Preoperative meticulous study of CT is very important for decision making in endoscopic frontal sinus surgery. Each anatomical variant in frontal recess area can be a predictor for operative easiness.
\end{abstract}

Keywords: Frontal Recess, Multiplanar CT, Sinusotomy, Agger Nasi Cell, Frontal Sinus Ostium, Frontoethmoidal Cells

\section{Introduction}

In the past three decades there has been a significant shift from external and headlight surgery to endoscopic sinus surgery (ESS). This dramatic change was initiated by the pioneering studies of Messerkling in which he demonstrated that each sinus has a predetermined mucociliary clearance pattern of drainage towards its natural ostium irrespective of additional openings that may have been created into the sinuses $^{(1,2)}$.

The endoscopic sinus surgery is increasingly becoming the mainstay of chronic rhinosinusitis management in the Medicare population ${ }^{(3)}$.

The advent of endoscopic technologies and techniques has expanded the limits of conventional endoscopic sinus surgery. The expanded endonasal approach describes a series of surgical modules in the sagittal and coronal planes that allow surgical access to the entire ventral skull base ${ }^{(4)}$.
The revolutionary changes in the surgical treatment of sinusitis in recent years, particularly in endonasal endoscopic surgery, require the clinician to have a precise knowledge of nasal sinus anatomy and of the large number of anatomical variants in the region, many of which are detectable only by the use of $\mathrm{CT}^{(5)}$.

A precise knowledge of the anatomy of the paranasal sinuses is essential for the clinician $^{(6)}$.Also,detailed knowledge of anatomic variations in paranasal sinus region is critical for surgeons performing endoscopic sinus surgery as well as for the radiologist involved in the preoperative work-up $^{(7)}$.

Knowledge of the structure and cells in frontal recess is the key for the surgeon to complete anddissect all the ethmoid cells and achieve an unblocked frontal drainage pathway ${ }^{(8,9)}$.

In thiswork,we studied the anatomical variants in frontal 
recess and their relation with operative easiness.

\section{Patients and Methods}

Patients:

This was a clinical trial prospective study included 50 Egyptian patients selected from the ENT department of Menofia University between June 2011 to November 2014.

These patients suffered from chronic frontal sinusitis refractory to medical treatment, while, those with massive inflammatory disease of specific infectios (e.g. rhinoscleroma), diffuse polyposis, malignancy, severe nasal trauma, foreign body, previous nasal surgery, atrophic diseases or systemic diseased patients not fit for surgery, were all excluded from our study.

Methods:

All patients were subjected to the following measures:

\subsection{Preoperative Measures}

- $\quad$ Full general and ENT history was taken.

- General examination.

- Clinical examination: complete ENT examination included endoscopic examination of the nose .

\subsection{Preoperative CT Examination}

Multislice CT (Aquilion, Toshiba, Japan) using slice thickness $(1-3 \mathrm{~mm})$ and reconstruction interval $(0.2-0.3 \mathrm{~mm})$ and different tube current (100-300mA) was used and coronal, axial and sagittal planes were studied.

\subsection{The CT Scan of All Patients Were Reviewed for the Following Findings}

\subsubsection{Prevalence and Size of Aggernasi Cells}

- Anteroposterior, Side to side and Craniocaudal diameters were estimated.

- Size of agar nasi cell was calculated by equation: $r_{1} \times r_{2} \times r_{3} \times \frac{4}{3} \times \pi$

Where:

- $\mathrm{r}_{1}$ : Anteroposterior diameter.

- $\mathrm{r}_{2}$ : Side to side diameter.

- $r_{3}$ : Craniocaudal diameter.

- $\pi$ : Constant equals 3.14.

- In this study we classified the aggernasi cells size as following:

\begin{tabular}{ll}
\hline Size of aggernasi cell & Range \\
\hline Small & $<500 \mathrm{~mm}^{3}$ \\
Medium & $500-3000 \mathrm{~mm}^{3}$ \\
Large & $>3000 \mathrm{~mm}^{3}$ \\
\hline
\end{tabular}

\subsubsection{Anteroposterior Diameter of Frontal Sinus Ostium}

In this study we measured the anteroposterior diameter of frontal sinus ostium (midpoint of internal nasal spine to skull base in the sagittal plane) and classified it as following:

\begin{tabular}{ll}
\hline Anteroposterior diameter & Range \\
\hline Small & $3-<6 \mathrm{~mm}$ \\
Medium & $6-<9 \mathrm{~mm}$ \\
Large & $>9 \mathrm{~mm}$ \\
\hline
\end{tabular}

\subsubsection{Frontoethmoidal Air Cells Including}

- Frontal cell, type 1.

- $\quad$ Frontal cell, type 2.

- $\quad$ Frontal cell, type 3.

- $\quad$ Frontal cell, type 4.

- Supraorbital ethmoid cell.

- Frontal bullar cell.

- Suprabullar cell.

- Interfrontal sinus septal cell.

The superior attachment type of the Uncinate process.

\section{Operative Procedure}

All procedures were done under general anaesthesia with hypotention as (Draf type IIa) endoscopic frontal sinosotomy ${ }^{(10)}$

\section{Intra Operative Assessment}

In this study we evaluated:

a) Time of frontal sinus surgery (on each side).

b) Easiness of surgery: visual analogue scale from 1-10 score according to surgeon questionnaire.

c) External work: trephine or osteoplastic flap. Grading of surgical easiness:

\begin{tabular}{llll}
\hline & Easy & Difficult & Very difficult \\
\hline Time & $<20$ minutes & $20-40$ minutes & $>40$ minutes \\
Easiness by VAS & $7-10$ & $4-6$ & $1-3$ \\
External work & - & - & + \\
\hline
\end{tabular}

\section{Postoperative Measures}

- $\quad$ All patients were discharged after 48 hours.

- $\quad$ Following up of all patients in: second day, first week, second week, third week and third month was done for:

- Postoperative patency by endoscopic examination.

- Alleviation of symptoms and Degree of patient satisfaction: by visual analogue scale from $0-10$.

Visual analogue scale for alleviation of symptoms and patients satisfaction:

\begin{tabular}{llll}
\hline & Good & Fair & Bad \\
\hline Visual analogue scale & $7-10$ & $4-7$ & $0-3$ \\
\hline
\end{tabular}

\section{Results}

This study was conducted on 50 patients 29 male \& 21 female their ages ranged from $16 \mathrm{ys}$ to $65 \mathrm{ys}$ with mean+SD age of $37.9+14.29 \mathrm{ys}$ 
Table (1). Prevalence of Aggarnasi cell.

\begin{tabular}{llll}
\hline Aggernasi cell & Number of Patients & \% & Number of Sides \\
\hline Unilateral & 9 & 18 & 9 \\
Bilateral & 38 & 76 & 76 \\
Total number & 47 & 94 & 85 \\
\hline
\end{tabular}

Table (2). Measurements of different diameters of aggernasi cells in millimeter.

\begin{tabular}{llll}
\hline Aggernasi Cell Diameters & Anteroposterior & Side to Side & Height \\
\hline Mean + SD & $6.5+4.56$ & $5+3.25$ & $7.7+4.78$ \\
Minimum value & 2 & 2 & 2 \\
Maximum value & 13 & 10 & 15 \\
\hline
\end{tabular}

Table (3). Volume of aggernasi cell.

\begin{tabular}{llll}
\hline volume of aggernasi Cell & Range & Number of sides & \% \\
\hline Absent & & 15 & 15 \\
Small & $<500 \mathrm{~mm}^{3}$ & 8 & 8 \\
Medium & $500-3000 \mathrm{~mm}^{3}$ & 65 & 65 \\
Large & $>3000 \mathrm{~mm}^{3}$ & 12 & 12 \\
\hline
\end{tabular}

Table (4). Prevalence of fronto-ethmoidal air cells.

\begin{tabular}{|c|c|c|c|c|c|c|c|}
\hline & \multicolumn{2}{|c|}{ Unilateral } & \multicolumn{2}{|c|}{ Bilateral } & \multicolumn{2}{|l|}{ Total } & \multirow{2}{*}{ Sides $\mathbf{N}$. } \\
\hline & Pts. N. & $\%$ & Pts. $N$. & $\%$ & Pts. N. & $\%$ & \\
\hline Frontal cells type (1) & 3 & 6 & 9 & 18 & 12 & 24 & 21 \\
\hline Frontal cells type (2) & 2 & 4 & 5 & 10 & 7 & 14 & 12 \\
\hline Frontal cells type (3) & 1 & 2 & 6 & 12 & 7 & 14 & 13 \\
\hline Frontal cells type (4) & 0 & 0 & 0 & 0 & 0 & 0 & 0 \\
\hline Supraorbital ethmoid cell & 1 & 2 & 2 & 4 & 3 & 6 & 5 \\
\hline Frontal bullar cell & 1 & 2 & 3 & 6 & 4 & 8 & 7 \\
\hline Suprabullar cell & 1 & 2 & 7 & 14 & 8 & 16 & 15 \\
\hline Interfrontal sinus septal cell & 15 & & & $30 \%$ & & & \\
\hline
\end{tabular}

Table (5). Superior attachment of uncinate process.

\begin{tabular}{llll}
\hline Type of Attachment & Site of Insertion & Number of Sides & \% \\
\hline Type 1 & Lamina papyracea & 70 & 70 \\
Type 2 & Middle turbinate & 10 & 10 \\
Type 3 & Skull base & 6 & 6 \\
Type 4 & Lamina papyracea and the middle turbinate & 5 & 5 \\
Type 5 & Lamina papyracea and the skull base & 8 & 8 \\
Type 6 & Middle turbinate and the skull base & 1 & 1 \\
\hline
\end{tabular}

On our study of sagittal cuts the anteroposterior diameter of frontal sinus ostium ranging from minimum value of $3 \mathrm{~mm}$ to maximum value of $16 \mathrm{~mm}$ with a mean $+\mathrm{SD}$ of $8.5+4.63 \mathrm{~mm}$.

Table (6). Antero-posterior diameter of frontal sinus ostium.

\begin{tabular}{llll}
\hline Antero-posterior Diameter & Range & Number of Sides & \% \\
\hline Small & $3-<6 \mathrm{~mm}$ & 14 & 14 \\
Medium & $6-<9 \mathrm{~mm}$ & 60 & 60 \\
Large & $>9 \mathrm{~mm}$ & 26 & 26 \\
\hline
\end{tabular}

Table (7). Size of agar nasi cell and operative easiness.

\begin{tabular}{|c|c|c|c|c|c|c|c|}
\hline \multirow{2}{*}{ Volume of Aggernasi Cell } & \multirow{2}{*}{ N. of Sides } & \multicolumn{2}{|c|}{ Easy } & \multicolumn{2}{|c|}{ Difficult } & \multicolumn{2}{|c|}{ Very difficult } \\
\hline & & $\mathbf{N}$ & $\%$ & $\mathbf{N}$ & $\%$ & $\mathbf{N}$ & $\%$ \\
\hline Absent & 15 & 5 & 33.3 & 7 & 46.7 & 3 & 20 \\
\hline Small & 8 & 3 & 37.5 & 3 & 37.5 & 2 & 25 \\
\hline Medium & 65 & 65 & 100 & 0 & 0 & 0 & 0 \\
\hline Large & 12 & 12 & 100 & 0 & 0 & 0 & 0 \\
\hline P. value & & \multicolumn{2}{|c|}{$0.001 *$} & \multicolumn{2}{|c|}{$0.001 *$} & \multicolumn{2}{|c|}{$0.001 *$} \\
\hline
\end{tabular}


Table (8). Frontoethmoidal cells and operative easiness.

\begin{tabular}{|c|c|c|c|c|c|c|c|c|}
\hline & \multirow{2}{*}{$\mathbf{N}$} & \multicolumn{2}{|c|}{ Easy } & \multicolumn{2}{|c|}{ Difficult } & \multicolumn{2}{|c|}{ Very difficult } & \multirow{2}{*}{$\mathbf{P}$} \\
\hline & & $\mathbf{N}$ & $\%$ & $\mathbf{N}$ & $\%$ & $\mathbf{N}$ & $\%$ & \\
\hline Frontal cells type (1) & 21 & 21 & 100 & 0 & 0 & 0 & 0 & $0.001 *$ \\
\hline Frontal cells type (2) & 12 & 12 & 100 & 0 & 0 & 0 & 0 & $0.001^{*}$ \\
\hline Frontal cells type (3) & 13 & 3 & 23 & 8 & 61.5 & 2 & 15.5 & $0.023^{*}$ \\
\hline Supraorbital ethmoid cell & 5 & 2 & 40 & 1 & 20 & 2 & 40 & 0.740 \\
\hline Frontal bullar cell & 7 & 6 & 86 & 1 & 14 & 0 & 0 & $0.001 *$ \\
\hline suprabullar cell & 15 & 13 & 86.7 & 2 & 13.3 & 0 & 0 & $0.001 *$ \\
\hline Interfrontal sinus septal & 15 & 9 & 60 & 4 & 26.7 & 2 & 13.3 & $0.020 *$ \\
\hline
\end{tabular}

Table (9). Superior attachment of uncinate process and operative easiness.

\begin{tabular}{|c|c|c|c|c|c|c|c|c|}
\hline \multirow{2}{*}{ Type of Attachment } & \multirow{2}{*}{$\mathbf{N}$} & \multicolumn{2}{|c|}{ Easy } & \multicolumn{2}{|c|}{ Difficult } & \multicolumn{2}{|c|}{ Very difficult } & \multirow{2}{*}{$\mathbf{P}$} \\
\hline & & $\mathbf{N}$ & $\%$ & $\mathbf{N}$ & $\%$ & $\mathbf{N}$ & $\%$ & \\
\hline Type 1 & 70 & 65 & 92.8 & 3 & 4.2 & 2 & 3 & $0.001 *$ \\
\hline Type 2 & 10 & 10 & 100 & 0 & 0 & 0 & 0 & $0.001 *$ \\
\hline Type 3 & 6 & 6 & 100 & 0 & 0 & 0 & 0 & $0.001 *$ \\
\hline Type 4 & 5 & 2 & 40 & 2 & 40 & 1 & 20 & 0.740 \\
\hline Type 5 & 8 & 4 & 50 & 2 & 25 & 2 & 25 & 0.472 \\
\hline Type 6 & 1 & 1 & 100 & 0 & 0 & 0 & 0 & 0.223 \\
\hline
\end{tabular}

Table (10). Anteroposterior diameter of frontal sinus ostium and operative easiness.

\begin{tabular}{llllllll}
\hline \multirow{2}{*}{ A-P diameter of F.S.O. } & \multirow{2}{*}{ N. of sides } & Easy & \multicolumn{2}{c}{ Difficult } & \multicolumn{3}{c}{ Very difficult } \\
\cline { 3 - 8 } & & $\mathbf{N}$ & $\mathbf{\%}$ & $\mathbf{N}$ & $\mathbf{\%}$ & $\mathbf{N}$ & $\mathbf{\%}$ \\
\hline Small & 14 & 5 & 35 & 4 & 30 & 5 & 35 \\
Medium & 60 & 50 & 83.3 & 10 & 16.7 & 0 & 0 \\
Large & 26 & 26 & 100 & 0 & 0 & 0 & 0 \\
P. value & & $0.001 *$ & & $0.029 *$ & & $0.001 *$ \\
\hline
\end{tabular}

The total group operative easiness, 80 sides were easy $(80 \%), 14$ sides were difficult $(14 \%)$ and 6 side were very difficult $(6 \%)$. In our series, all cases was operated by doing
Draf type IIa operation and there was no case needed for external work assistance (trephine or osteoplastic flap).

Table (11). Postoperative patency (Endoscopic view).

\begin{tabular}{lllll}
\hline \multirow{2}{*}{ Postoperative Patency } & Patent & & \multicolumn{2}{l}{ Non patent } \\
\cline { 2 - 5 } & $\mathbf{N}$ & $\mathbf{\%}$ & $\mathbf{N}$ & $\mathbf{\%}$ \\
\hline $1^{\text {st }}$ week & 60 & 60 & 40 & 40 \\
$2^{\text {nd }}$ week & 75 & 75 & 25 & 25 \\
$3^{\text {rd }}$ week & 90 & 90 & 10 & 10 \\
$3^{\text {rd }}$ month & 95 & 95 & 5 & 5 \\
\hline
\end{tabular}

Table (12). Alleviation of symptoms and patients satisfaction.

\begin{tabular}{lllllll}
\hline & Good & & Fair & & Bad \\
\cline { 2 - 7 } & $\mathbf{N}$ & $\mathbf{0}$ & $\mathbf{N}$ & $\mathbf{\%}$ & $\mathbf{N}$ & $\mathbf{\%}$ \\
\hline $1^{\text {st }}$ week & 25 & 50 & 15 & 30 & 10 & 20 \\
$2^{\text {nd }}$ week & 32 & 64 & 12 & 24 & 6 & 12 \\
$3^{\text {rd }}$ week & 38 & 76 & 7 & 14 & 5 & 10 \\
$3^{\text {rd }}$ month & 42 & 84 & 4 & 8 & 4 & 8 \\
\hline
\end{tabular}


Cases
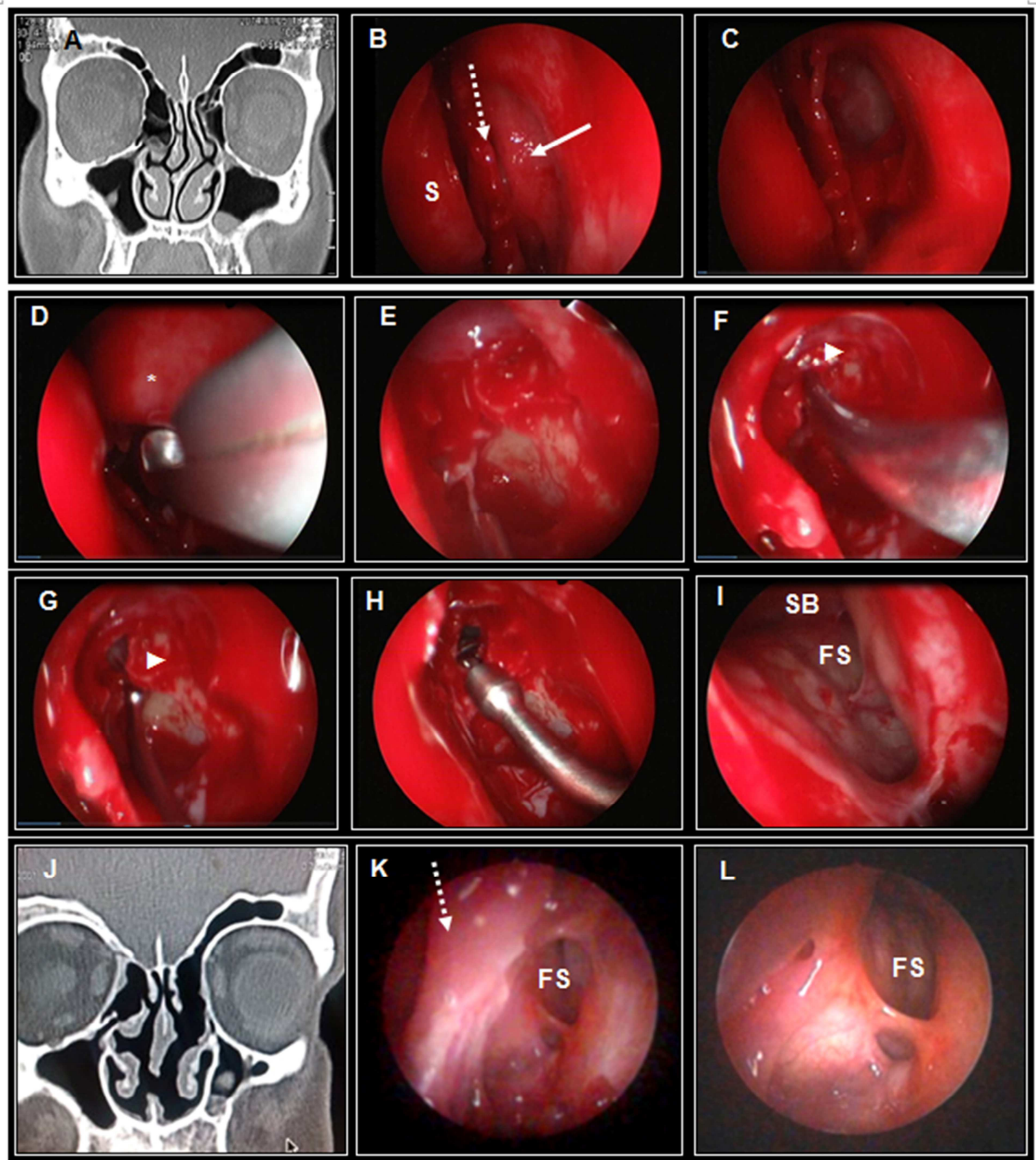

Figure (1). (A)Preoperative Coronal CT of bilateral supraorbital cells. (B) Left nasal cavity Shows $S$ nasal septum, Dotted arrow is the middle turbinate with trimmed anterior face, Solid arrow indicates the uncinate process. (C) Shows left uncinectomy. (D) Shows AggarNasi cell (*) punch-out using Hajek forceps.

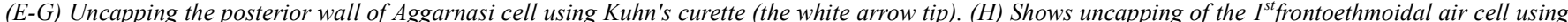
frontal sinus mushroom forceps $70^{\circ}$. (I) Frontal sinus (F.S.) ostium had widened showing the posterior table of frontal sinus; anterior skull base (SB). (J) Coronal CT 3 months postoperative. $(K, L)$ Show endoscopic view of postoperative patency 3 months postoperative by 30 degrees angled telescope. Dotted arrow indicates axilla of left middle turbinate, FS is that frontal sinus.

\section{Discussion}

In our study, we studied the association of anatomical variants in frontal recess area and easiness of operations according the time of frontal sinustomy, easiness of operation under visual analogue scale done by the surgeon and need for open procedure assessing endoscopic sinustomy.

In all cases we didn't obligate to do trephine or any external extra work. We found that in absent agar nasi cell 5 sides were easy $(33.3 \%), 7$ side were difficult $(46.7 \%)$ and 3 sides of $(20 \%)$ were very difficult. In small sized agar nasi cells we 
found 3 sides were easy in operation (37.5\%), 3 sides were difficult $(37.5 \%)$ and 2 sides were very difficult (25\%). In medium sized agar nasi cells, we found that all sides were easy $(100 \%)$. In large sized agar nasi cell all 12 sides were easy $(100 \%)$. All the results indicated that in small the sized agar nasi cell, surgery is difficult and on increase the size of agar nasi cell, surgery becomes more easy.

About the frontoethmoidal cells and operative easiness; In frontal cell type (1) all 21 sides were easy in operation (100\%). Frontal cell type (2) all 12 sides were easy in operation (100\%). In frontal cell type (3), 3 sides were easy in operation (23\%), 8 sides were difficult $(61.5 \%)$ and 2 sides were very difficult (15.5\%). Supraorbital frontal air cells 2 sides were easy (40\%), 1 side was difficult $(20 \%)$ and 2 sides were very difficult (40\%). Frontal bullar cells 7 sides were easy (86\%) and 1 side difficult (14\%). Suprabullar frontal cell we found 13 sides to were easy $86.7 \%$ and 2 sides difficult $(13.3 \%)$. Interfrontal sinus septal cell 9 cases were easy $(60 \%), 4$ cases were difficult $(26.7 \%)$ and 2 cases were very difficult $(13.3 \%)$. In our series, we didn't find type (4) frontoethmoidal cells. These results indicate that type (3) frontoethmoidal cells and interfrontal sinus septal cell are more difficult in endoscopic surgery than other frontoethmoial cells apart of type (4) frontoethmoidal cells which we didn't found in our cases.

For the superior attachment of uncinate process and operative easiness.In type (1) attachment 65 sides were easy $(92.8 \%), 3$ sides were difficult $(4.2 \%)$ and 2 sides were very difficult (3\%). In type (2) attachment all 10 sides were easy (100\%). In type (3) attachment all 6 sides were easy (100\%). In type (4) attachment 2 sides were easy (40\%), 2 sides were difficult (40\%) and 1 sides was very difficult (20\%). In type (5) attachment 4 sides were easy $(50 \%), 2$ sides were difficult $(25 \%)$ and 2 sides were very difficult (25\%). In type (6) attachment 1 side was easy (100\%).

For the anteroposterior diameter of frontal sinus ostium and operative easiness. In small anteroposter diameter of F.S.O. 5 sides were easy (35\%), 4 sides were difficult $(30 \%)$ and 5 sides were very difficult (35\%). In medium size anteroposterior diameter of F.S.O. 50 sides were easy (83.3\%), 10 sides were difficult $(16.7 \%)$. In large diameter 26 sides were easy $(100 \%)$. Showing that on increased anteroposterior dimeter surgery becomes easier.

In our study the total group operative easiness, 80 sides were easy $(80 \%), 14$ sides were difficult $(14 \%)$ and 6 side were very difficult $(6 \%)$. In our series the postoperative patency (endoscopic view). In the first week 60 sides were patent $(60 \%)$ and 40 sides were not patent $(40 \%)$. In the second week 75 sides were patent $(75 \%)$ and 25 sides were not patent $(25 \%)$. In the third week 90 sides were patent $(90 \%)$ and 10 sides were not patent (10\%). In the third month 95 sides were patent $(95 \%)$ while 5 sides were not patent $(5 \%)$.

In our study the alleviation of symptoms and patients satisfaction after visual analogue scale. In the first week 25 patients were satisfied (50\%), 15 were fairly satisfied (30\%) and 10 patients were badly satisfied (20\%). In the second week 32 patients were satisfied (64\%), 12 patients were fairly satisfied $(24 \%)$ and 6 patients were badly satisfied $(12 \%)$. In the third week 38 patients were satisfied (76\%), 7 patients were fairly satisfied (14\%) and 5 patients were badly satisfied $(10 \%)$. In the third month 42 patients were satisfied (84\%), 4 patients were fairly satisfied ( $8 \%$ ) and 4 patients were badly satisfied (8\%).

\section{Conclusion}

- $\quad$ Preoperative meticulous study of CT is very important for decision making in endoscopic frontal sinus surgery to predict intraoperative encounters.

- $\quad$ Each anatomical variant in frontal recess area can be a predictor for operative easiness, Though necessitating for: more skilled hand surgeon, intraoperative navigation or external frontal surgery.

\section{References}

[1] Mizukoshi O. Clinical Otorhinolaryngology and Head and Neck Surgery. Vol. 6A. 1989.

[2] Stammberger H., Kopp W., Dekornfeld T.J. Special endoscopic anatomy. In Stammberger H, Hawke M, Kopp W (eds). Functional endoscopic sinus surgery: the Messerklinger technique. Philadelphia. BC Decker Publishers: 1991: 61-90.

[3] Schaefer J.P. The lateral wall of the cavumnasi in man, with special reference to the various developmental stages. J. Morph, 1910. 24: p. 613-707.

[4] Zuckerkandl E. Normale und pathologische Anatomie der Nasenhöhle und ihrer pneumatischen Anhänge. Band 2te Auflage, Wilhelm BraumUller, Wien \& Leipzig, 1893.

[5] Coates M.H., Whyte A.M. and Earwaker J.W.S. Frontal recess air cells: spectrum of CT appearances. Australasian Radiology. 2003; 47: 4-10.

[6] Wormald P.J. Endoscopic sinus surgery anatomy, three-dimensional reconstruction and surgical technique. ThiemrNew York. Stuttgart. Second Edition, 2007; 43-81.

[7] Bolger W.E., ButzinC.A., Parsons D.S.Paranasal sinus bony anatomic variations and mucosal abnormalities: CT analysis for endoscopic sinus surgery. Laryngoscope. 1991; 101, 56-64.

[8] Lee W.T., Kuhn F.A., Citardi M.J.: 3D computed tomographic analysis of frontal recess anatomy in patients without frontal sinusitis. Otolaryngology-Head and neck surger. 2004; 131: 164-73.

[9] Wormald P.J. Anatomy of the frontal recess and frontal sinus with three-dimensional reconstruction/endoscopic sinus surgery: anatomy, three-dimensional reconstruction, and surgical technique. $2^{\text {nd }}$. New York: Thieme; 2008: 43-82.

[10] Draf W. Endonasal Frontal Sinus Drainage Type I-III. In: Kountakis SE, Senior BA, Draf W, eds. Berlin, Germany: Springer-Verlag; 2005;219-233 